\title{
COPD as a risk factor of the complications in lower limb arthroplasty: a patient-matched study
}

This article was published in the following Dove Press journal:

International Journal of COPD

\author{
Antonio Klasan' \\ Philipp Dworschak' \\ Thomas Jan Heyse' \\ Steffen Ruchholtz' \\ Peter Alter ${ }^{2}$ \\ Claus Franz Vogelmeier ${ }^{2}$ \\ Patrick Schwarz ${ }^{2}$ \\ 'Department of Orthopedics and \\ Traumatology, University Hospital \\ Marburg, Marburg, Germany; \\ ${ }^{2}$ Department of Pulmonary and \\ Critical Care Medicine, University \\ Hospital Marburg, Marburg, Germany
}

Purpose: A relevant proportion of patients undergoing joint replacement surgery for the treatment of osteoarthritis exhibit COPD. This coincidence may result from an increased prevalence of both the diseases in elderly patients. In this study, COPD, which is known to be associated with a variety of comorbidities, and its potential interactions, eg, mediated via systemic inflammation, are discussed. The purpose of the present study was to identify the role of COPD as an independent risk factor for complications after total knee and hip arthroplasty.

Patients and methods: In a monocentric patient cohort of 2,760 arthoplasties, propensity score matching was done using the following factors: sex, age, replaced joint, American Society of Anesthesiologists' score, body mass index, hypertension, chronic heart disease, anticoagulation, diabetes mellitus, chronic renal deficiency, and actual smoking status to create 224 pairs. Both the pre-matched differences and the results after propensity score matching were statistically analyzed with $p \leq 0.05$ being defined as statistically significant.

Results: All confounders were eliminated after matching. Preoperatively measured C-reactive protein and leukocytes were higher in the COPD group $(p<0.001 ; p=0.01$, respectively). Intensive care unit admission was higher for COPD patients $(p=0.023)$. Pneumonia occurred in patients with COPD only ( $p=0.024)$. There was a trend (not significant) toward a higher rate of wound infections, increased transfusion of red blood cells, and a prolonged hospital stay in patients with COPD

Conclusion: COPD was associated with an increased length of hospital stay, a higher risk of pneumonia and wound infection, higher general complications, and an increased need for red blood cell transfusion. It is thus recommended to enhance the implementation of pneumonia prevention programs on surgical wards.

Keywords: COPD, pneumonia, arthroplasty, complication, transfusion, comorbidity

\section{Plain language summary}

COPD is a common disease, and its incidence increases with age. With increasing age, the rate of the degenerative changes in lower limb joints also increases. Thus, the number of COPD patients undergoing lower limb arthroplasty increases. Subsequent to exhausted conservative treatment options, joint replacement remains as mainstay of therapy. The purpose of this study was to determine the role of COPD in these surgical procedures. A statistical matched pair analysis was used to create 224 pairs of patients with and without COPD. COPD patients had higher serum C-reactive protein and leukocytes preoperativley. They were more frequently admitted to the intensive care unit, and the rates of wound infections, the red blood cell transfusions, and the hospitalization time were slightly higher. Importantly, pneumonia occurred in only the COPD group. In summary, COPD as a disease is somehow underestimated by the orthopedic surgeons but can have serious effects in the patients. Pneumonia prevention programs on surgical wards have already been established and should be used more widely.
Correspondence: Antonio Klasan Department of Orthopedics and Traumatology, University Hospital Marburg, Baldingerstrasse, D-35043 Marburg, Germany

Tel $+49642 I 5864715$

Fax +49 642I 5867007

Email klasan.antonio@me.com 


\section{Introduction}

COPD is observed in a relevant proportion of elderly patients undergoing joint replacement surgery. It is associated with a broad variety of comorbidities including osteoarthritis, rheumatoid arthritis, and other inflammatory diseases as well as cardiovascular risk factors and manifest diseases. ${ }^{1}$ There are mutual interactions between COPD and comorbidities regarding disease severity and prognosis. Independent of potential pathophysiological interactions between COPD and osteoarthritis (eg, systemic inflammation), the prevalence of both the diseases increases with patient's age. Thus, COPD might be a comorbidity and risk factor in elderly patients undergoing elective arthroplasty.

COPD is mainly caused by cigarette smoking, ${ }^{2}$ but other factors such as indoor air pollution ${ }^{3}$ or environmental exposure $^{4}$ can also contribute to the development of the disease. The prevalence of COPD is higher in elderly ( $>75$ years) than in younger subjects. ${ }^{5}$ Osteoarthritis is commonly observed in older people, ${ }^{6,7}$ which is suggestive of a large overlap of both the diseases. The prevalence of COPD in the adult population is about $10 \%$, with heterogeneity across centers and sex. ${ }^{8}$

Currently, joint replacement surgery is the predominant type of therapy for osteoarthritis of the lower joints. An increasing incidence is suspected for the upcoming years ${ }^{9}$ with more than 300,000 joint replacements being performed in Germany annually. ${ }^{10}$ It is well-known that smoking increases the risk of complications in both hip ${ }^{11}$ and knee replacement surgeries. ${ }^{12}$ These complications appear to be mediated by an impaired inflammatory response. ${ }^{13}$ Patients with COPD have higher rates of surgery-related complications than patients without COPD. ${ }^{14}$ However, whether the presence of COPD is an independent risk factor regardless of the smoking status is yet unknown. The results of this study may impact approximately 30,000 (10\%) patients annually in Germany alone.

The aim of this study was to evaluate the risk factors and complications in a propensity score-matched population, with and without COPD, receiving lower limb arthroplasty.

\section{Patients and methods}

A total of 2,760 patients receiving primary total knee or hip arthroplasty between January 1, 2010, and December 31, 2014, have been included in this monocentric study. The hospital was an orthopedic clinic with a capacity of 80 beds, specialized in large joint arthroplasty. Patients undergoing revision surgery, fracture, and tumor prostheses were excluded from the study. Thus, a total of 1,416 hip replacements and 1,344 knee replacements data were examined. All knee replacements were performed using the medial parapatellar approach, and only cemented and cruciate retaining primary implants were used. Hip replacements were done through the direct anterior approach in 847 patients (59\%) and through the anterolateral Watson-Jones approach in 569 cases (41\%).

Data about the in-hospital stay were collected and anonymized. Preoperative assessed data were derived from the patients' history and the anesthesiological evaluation. Based on these data, 224 patients with COPD were identified. Due to the retrospective nature, data on COPD severity level were only partial or outdated and were disregarded. The flowchart of patient selection is shown in Figure 1. The diagnosis was derived from the patient's history or based on the anesthesiologist's discretion of the individual medication. Patient matching was done in a 1:1 manner by using the following confounding characteristics: sex, age, replaced joint, American Society of Anesthesiologists' (ASA) score, body mass index (BMI), arterial hypertension, chronic heart disease, anticoagulation, diabetes mellitus, and chronic renal deficiency. ASA score was determined by the anesthesiologist. Postoperative admission to the intensive care unit (ICU) was the individual decision of the anesthesiologist and was based on multiple factors such as occupancy of the ICU, prolonged surgery, and time of surgery during the day. Development of nosocomial pneumonia was well documented with laboratory results and X-rays, in accordance with the guidelines. ${ }^{15}$

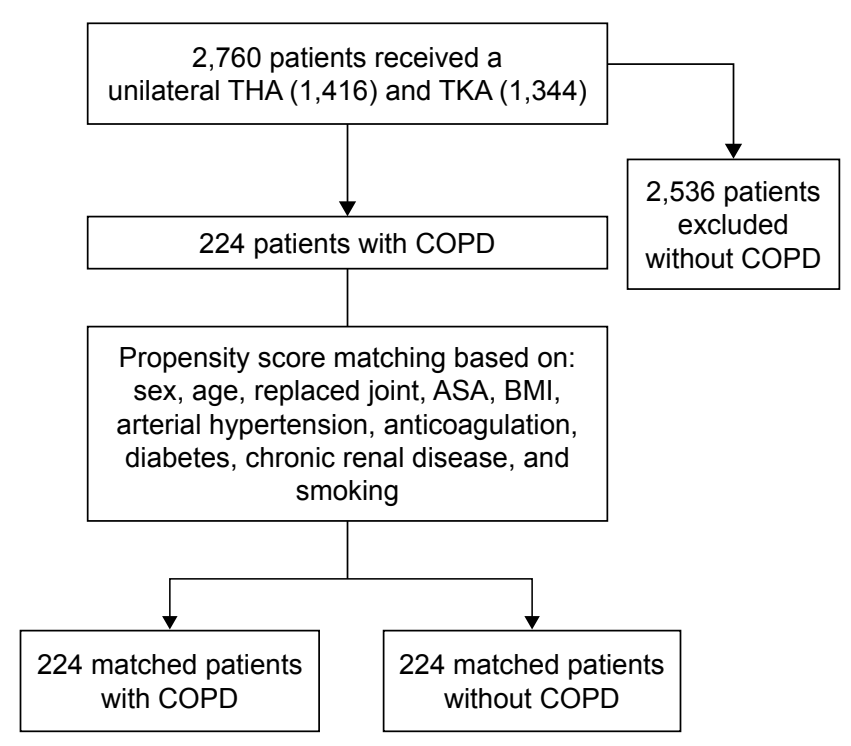

Figure I Flowchart of the patients included in the study and patient matching. Abbreviations: ASA, American Society of Anaesthesiologists; BMI, body mass index; THA, total hip arthroplasty; TKA, total knee arthroplasty. 


\section{Statistical analysis and propensity score matching}

In order to account for all the covariates and thus to reduce the bias in an uncontrolled, retrospective cohort, propensity score matching was performed. ${ }^{16}$ To obtain propensity scores of COPD, a univariate logistic regression analysis using the 10 variables presented in Table 1 was performed. Comparisons between the two groups were performed using the $\chi^{2}$ test for categorical variables and one-way analysis of variance or Student's $t$-test for continuous variables. Before matching, the BMI of non-COPD patients was lower, the rate of all preoperative comorbidities was lower, and average ASA score was much lower (Table 1). After propensity score matching, no differences were found in the demographic data and preoperative risk factors between the two groups (Table 1). Regional anesthesia was the predominant method in both the groups.

Data were analyzed by using SPSS version 23.0 (IBM Corporation, Armonk, NY, USA). Data were expressed as mean \pm standard deviation (SD) and median with ranges or proportions. Statistical significance was set at $p \leq 0.05$.

\section{Ethics approval and informed consent}

The study was reviewed and approved by the ethical committee under the accession number F-2015-010 by the Ethical Board of the Medical Chamber of Stuttgart, BadenWürttemberg, Germany. Patient consent was not required for a retrospective data analysis. Patient data have been collected in a pseudonym fashion. Only the first author has access to patient names.

\section{Results}

The mean age $( \pm \mathrm{SD})$ of the complete cohort was $69.6( \pm 9.9)$ years, the patient age in the matched cohorts was minimally higher, that is, $71.0( \pm 9.25)$ years for non-COPD and 70.6 $( \pm 9.2)$ years for COPD patients (Table 1). The complete cohort included 1,088 men (39.4\%), and the matched cohorts had a slightly lower proportion of male patients $(36.6 \%$, 82 individuals). The COPD group had a $1.9 \pm 1.3 \mathrm{~kg} / \mathrm{m}^{2}$ higher average BMI than the complete cohort; however, the matched cohort had almost the same BMI (Table 1). Regional anesthesia was used in $66 \%$ of the cases (Table 1). One of the most impacting confounders is the number of ASA 3 patients within the cohort. The difference between the COPD group and the unmatched cohort was $27.9 \%$ versus $60 \%$. By patient matching, this confounder has been eliminated $(p=0.420)$. In total, all confounders were equalized by the propensity score matching.

Preoperatively measured C-reactive protein (CRP) was higher in the COPD group and was statistically significant (Table 2). The same applies for the leukocytes (Table 2). The CRP measurement in the COPD group is, however, slightly above the normal range of $<5 \mathrm{mg} / \mathrm{L}$.

COPD patients had a higher risk of ICU admission postoperatively ( $p=0.023$ ), although no difference in the length of ICU stay occurred (Table 2). Pneumonia occurred only in the COPD group for a total of five times with a clear statistical difference $(p=0.024)$ (Table 2$)$. Three of the patients with pneumonia were admitted to the ICU directly postoperatively, and two were not. The patients who developed pneumonia during the hospital stay had an average length of stay of $19.2 \pm 5.3$ days.

Table I Preoperative characteristics and risk factors for study patients

\begin{tabular}{|c|c|c|c|c|c|c|}
\hline \multirow[t]{2}{*}{ Variables } & \multicolumn{3}{|l|}{ All study patients } & \multicolumn{3}{|c|}{ Matched groups } \\
\hline & $\begin{array}{l}\text { Non-COPD } \\
\text { group }(n=2,536)\end{array}$ & $\begin{array}{l}\text { COPD group } \\
(n=224)\end{array}$ & $p$-value & $\begin{array}{l}\text { Non-COPD } \\
\text { group }(n=224)\end{array}$ & $\begin{array}{l}\text { COPD group } \\
(n=224)\end{array}$ & $p$-value \\
\hline Age (years) & $69.5 \pm 9.8$ & $70.6 \pm 9.2$ & 0.116 & $71.0 \pm 9.25$ & $70.6 \pm 9.2$ & 0.647 \\
\hline Male, n (\%) & $\mathrm{I}, 026(40.4)$ & $82(36.6)$ & 0.600 & $82(36.6)$ & $82(36.6)$ & 0.883 \\
\hline BMI $\left(\mathrm{kg} / \mathrm{m}^{2}\right)$ & $28.6 \pm 5.2$ & $30.5 \pm 6.5$ & $<0.001$ & $30.2 \pm 6.2$ & $30.5 \pm 6.5$ & 0.634 \\
\hline THA, n (\%) & $1,419(51.4)$ & $106(47.3)$ & 0.262 & $104(46.4)$ & $106(47.3)$ & 0.962 \\
\hline Regional anesthesia, n (\%) & $\mathrm{I}, 614(63.6)$ & |4| (62.9) & 0.900 & $149(66.5)$ & I4I (62.9) & 0.574 \\
\hline Arterial hypertension, $\mathrm{n}(\%)^{\mathrm{a}}$ & $1,936(70.1)$ & $185(82.5)$ & 0.537 & $190(84.8)$ & $185(82.5)$ & 0.824 \\
\hline Anticoagulation, $\mathrm{n}(\%)^{\mathrm{a}}$ & $630(22.8)$ & $67(29.9)$ & 0.018 & $66(29.4)$ & $67(29.9)$ & 0.970 \\
\hline $\mathrm{CHD}, \mathrm{n}(\%)^{\mathrm{a}}$ & $533(19.3)$ & $81(36.1)$ & 0.027 & 76 (33.9) & $81(36.1)$ & 0.722 \\
\hline Diabetes mellitus, $\mathrm{n}(\%)^{\mathrm{a}}$ & $422(15.2)$ & $49(21.8)$ & 0.951 & $58(25.9)$ & $49(21.8)$ & 0.299 \\
\hline CRD, n (\%) ${ }^{\mathrm{a}}$ & $498(18)$ & $57(25.4)$ & 0.814 & $52(23.2)$ & $57(25.4)$ & 0.536 \\
\hline ASA $3, \mathrm{n}(\%)^{\mathrm{a}}$ & 77 I (27.9) & $136(60)$ & $<0.001$ & $133(59.3)$ & $136(60)$ & 0.420 \\
\hline
\end{tabular}

Note: ${ }^{\text {Risk factors. }}$

Abbreviations: BMI, body mass index; THA, total hip arthroplasty; CHD, chronic heart disease; CRD, chronic renal disease; ASA 3, American Society of Anaesthesiologists' score 3. 
Table 2 Differences in postoperative complications and parameters

\begin{tabular}{|c|c|c|c|}
\hline Variables & $\begin{array}{l}\text { Non-COPD } \\
\text { group } \\
(n=224)\end{array}$ & $\begin{array}{l}\text { COPD } \\
\text { group } \\
(n=224)\end{array}$ & $p$-value \\
\hline CRP, preoperative (mg/L) & $4.4 I \pm 3.79$ & $6.55 \pm 6.88$ & $<0.001$ \\
\hline Leukocytes, preoperative $\times 10^{9} / \mathrm{L}$ & $7.19 \pm 2.191$ & $7.76 \pm 2.46$ & 0.010 \\
\hline Intensive care admission, $\mathrm{n}(\%)$ & $94(41.9)$ & $119(53.1)$ & 0.023 \\
\hline Pneumonia, n (\%) & $0(0)$ & $5(2.2)$ & 0.024 \\
\hline Length of stay, days, n (\%) & $13.76(6.4)$ & $14.13(6.5)$ & 0.556 \\
\hline Length of stay in ICU, days, $\mathrm{n}(\%)$ & $1.02(0.2)$ & $1.03(0.2)$ & 0.075 \\
\hline General complication rate, $\mathrm{n}(\%)$ & $36(16.0)$ & $47(20.1)$ & 0.255 \\
\hline Wound infection rate, $\mathrm{n}(\%)$ & $4(0.17)$ & $7(0.3)$ & 0.353 \\
\hline Transfusion rate, $\mathrm{n}(\%)$ & $20(8.9)$ & $30(13.4)$ & 0.126 \\
\hline
\end{tabular}

Abbreviations: CRP, C-reactive protein; ICU, intense care unit.

\section{Discussion}

To identify the risk factors and postoperative complications of COPD and non-COPD patients undergoing lower limb arthroplasty, a propensity score-matching analysis was performed. It was shown that both CRP and the leukocyte count at preoperative assessment were significantly higher in patients with COPD than in patients without COPD. This may reflect a chronic state of low-level inflammation in these patients.

Using propensity score matching, differences between both the groups were observed. During the preoperative assessment, both proinflammatory markers, that is, CRP and leukocytes, were significantly higher in COPD patients, which may represent a chronic state of the disease. ${ }^{17}$

Perioperative admission to ICU was more frequent in patients with COPD when compared to patients without COPD, which is comparable to a previous report. ${ }^{18}$

The rate of pneumonia in the present study was $1.1 \%$ overall, or $2.2 \%$ in the COPD group. A large recent retrospective analysis showed an overall pneumonia rate of $0.3 \%{ }^{19}$ and did not analyze COPD patients specifically. Pneumonia mortality rate was $4 \%$, an occurrence not observed in our study.

The proportion of regional anesthesia was similar in both the groups; however, pneumonia occurred only in COPD patients. Even though the number of these patients was low, the difference was statistically significant. Two of these patients received general anesthesia and three patients received regional anesthesia. It has been shown that reduced use of general anesthesia lowers postoperative pneumonia in COPD patients. ${ }^{20}$

Although not statistically significant, the increased wound infection rate, and need for red blood cell transfusion, and overall complication rate were all higher in the COPD group. To confirm these differences, larger COPD cohorts are needed, especially in orthopedic surgery.

In two studies, an increased hospital readmission and pneumonia rate (1.1\% vs $3.7 \%)$, as well as an increased length of stay, but no higher infection or mortality rate was observed. ${ }^{21,22}$ However, the study was a nationwide casecontrol study without propensity matching and with different groups as well as unaddressed confounding factors.

Besides these studies, ${ }^{21,22}$ no other studies have been published, evaluating COPD as a risk factor in orthopedic surgery, regardless of the actual smoking status. The strength of the present study is a large monocentrical cohort, with standardized procedures, pre-, intra-, and postoperatively. The main limitation of the study is the retrospective and uncontrolled nature. However, the confounding factors were drastically reduced using patient matching except for ICU admission, which was an individual decision of the anesthesiologist, not based on a clinical necessity. Another limitation that would certainly be of great statistical significance is the lack of COPD severity levels, due to the retrospective nature of the study.

The implications of this study, applied nationwide in Germany, mean that 660 patients with COPD would develop pneumonia during their hospital stay after lower limb arthroplasty and 26 patients would die as a direct result of their COPD. Pneumonia prevention programs on surgical wards are already used and include deep breathing exercises, oral hygiene with chlorhexidine, $30^{\circ}$ upright position for eating with education for both the staff and the patient. Applying these techniques, the pneumonia rate can be reduced between $40 \%$ and $80 \% .^{23,24}$

We recommend a wider implementation of these methods to reduce the pneumonia rate in COPD patients after surgery.

\section{Conclusion}

Although somewhat underestimated by the orthopedic surgeons, COPD as a risk factor potentially bears serious implications on the patients, including a longer length of hospital stay, a higher risk of pneumonia and wound infection, and a higher general complication and red blood cell transfusion rate. A larger cohort prospective study should be performed to assess the role of COPD as an independent risk factor. Implementation of the pneumonia prevention programs on surgical wards should be more widespread.

\section{Author contributions}

Antonio Klasan and Patrick Schwarz contributed to data collection and created the first draft. Antonio Klasan performed 
data analysis. Peter Alter and Patrick Schwarz contributed to most of the revisions. All authors participated in conceptualizing the study, drafted the final article, approved the publication, and agreed to be accountable for all aspects of the work.

\section{Disclosure}

The authors report no conflicts of interest in this work.

\section{References}

1. Miller J, Edwards LD, Agusti A, et al. Comorbidity, systemic inflammation and outcomes in the ECLIPSE cohort. Respir Med. 2013; 107(9):1376-1384.

2. Kohansal R, Soriano JB, Agusti A. Investigating the natural history of lung function: facts, pitfalls, and opportunities. Chest. 2009;135(5): 1330-1341.

3. Orozco-Levi M, Garcia-Aymerich J, Villar J, Ramirez-Sarmiento A, Anto JM, Gea J. Wood smoke exposure and risk of chronic obstructive pulmonary disease. Eur Respir J. 2006;27(3):542-546.

4. Gan WQ, FitzGerald JM, Carlsten C, Sadatsafavi M, Brauer M. Associations of ambient air pollution with chronic obstructive pulmonary disease hospitalization and mortality. Am J Respir Crit Care Med. 2013;187(7):721-727.

5. Terzikhan N, Verhamme KM, Hofman A, Stricker BH, Brusselle GG, Lahousse L. Prevalence and incidence of COPD in smokers and non-smokers: the Rotterdam Study. Eur J Epidemiol. 2016;31(8): 785-792.

6. Prieto-Alhambra D, Judge A, Javaid MK, Cooper C, Diez-Perez A, Arden NK. Incidence and risk factors for clinically diagnosed knee, hip and hand osteoarthritis: influences of age, gender and osteoarthritis affecting other joints. Ann Rheum Dis. 2014;73(9):1659-1664.

7. Morri M, Forni C, Marchioni M, Bonetti E, Marseglia F, Cotti A. Which factors are independent predictors of early recovery of mobility in the older adults' population after hip fracture? A cohort prognostic study. Arch Orthop Trauma Surg. 2018;138(1):35-41.

8. Buist AS, McBurnie MA, Vollmer WM, et al. International variation in the prevalence of COPD (the BOLD Study): a population-based prevalence study. Lancet. 2007;370(9589):741-750.

9. Kurtz S, Ong K, Lau E, Mowat F, Halpern M. Projections of primary and revision hip and knee arthroplasty in the United States from 2005 to 2030. J Bone Joint Surg Am. 2007;89(4):780-785.

10. Kim SH, Gaiser S, Meehan JP. Epidemiology of primary hip and knee arthroplasties in Germany: 2004 to 2008. J Arthroplasty. 2012;27(10): $1777-1782$.
11. Kapadia BH, Issa K, Pivec R, Bonutti PM, Mont MA. Tobacco use may be associated with increased revision and complication rates following total hip arthroplasty. J Arthroplasty. 2014;29(4):777-780.

12. Kapadia BH, Johnson AJ, Naziri Q, Mont MA, Delanois RE, Bonutti PM. Increased revision rates after total knee arthroplasty in patients who smoke. J Arthroplasty. 2012;27(9):1690-1695.e1.

13. Sørensen LT. Wound healing and infection in surgery: the pathophysiological impact of smoking, smoking cessation, and nicotine replacement therapy: a systematic review. Ann Surg. 2012;255(6):1069-1079.

14. Kim HJ, Lee J, Park YS, et al. Impact of GOLD groups of chronic pulmonary obstructive disease on surgical complications. Int J Chron Obstruct Pulmon Dis. 2016;11:281-287.

15. Sanz Herrero F, Blanquer Olivas J. Microbiology and risk factors for community-acquired pneumonia. Semin Respir Crit Care Med. 2012; 33(3):220-231.

16. Rosenbaum $P$, Rubin D. The central role of the propensity score in observational studies for causal effects. Biometrika. 1983;70(1):41-55.

17. Ansar W, Ghosh S. C-reactive protein and the biology of disease. Immunol Res. 2013;56(1):131-142.

18. Courtney PM, Whitaker CM, Gutsche JT, Hume EL, Lee GC. Predictors of the need for critical care after total joint arthroplasty: an update of our institutional risk stratification model. J Arthroplasty. 2014;29(7): 1350-1354.

19. Bohl DD, Saltzman BM, Sershon RA, Darrith B, Okroj KT, Della Valle CJ. Incidence, risk factors, and clinical implications of pneumonia following total hip and knee arthroplasty. $J$ Arthroplasty. 2017;32(6):1991-1995.e1.

20. Hausman MS, Jewell ES, Engoren M. Regional versus general anesthesia in surgical patients with chronic obstructive pulmonary disease: does avoiding general anesthesia reduce the risk of postoperative complications? Anesth Analg. 2015;120(6):1405-1412.

21. Liao KM, Lu HY. A national analysis of complications following total hip replacement in patients with chronic obstructive pulmonary disease. Medicine (Baltimore). 2016;95(12):e3182.

22. Liao KM, Lu HY. Complications after total knee replacement in patients with chronic obstructive pulmonary disease: a nationwide case-control study. Medicine (Baltimore). 2016;95(37):e4835.

23. Kazaure HS, Martin M, Yoon JK, Wren SM. Long-term results of a postoperative pneumonia prevention program for the inpatient surgical ward. JAMA Surg. 2014;149(9):914-918.

24. Wren SM, Martin M, Yoon JK, Bech F. Postoperative pneumoniaprevention program for the inpatient surgical ward. J Am Coll Surg. 2010;210(4):491-495
International Journal of COPD

\section{Publish your work in this journal}

The International Journal of COPD is an international, peer-reviewed journal of therapeutics and pharmacology focusing on concise rapid reporting of clinical studies and reviews in COPD. Special focus is given to the pathophysiological processes underlying the disease, intervention programs, patient focused education, and self management protocols.

\section{Dovepress}

This journal is indexed on PubMed Central, MedLine and CAS. The manuscript management system is completely online and includes a very quick and fair peer-review system, which is all easy to use. Visit http://www.dovepress.com/testimonials.php to read real quotes from published authors. 